\title{
TRIZ ile Problem Çözmede Sorunun Yeniden Tanımlanması: Problem Formülasyonu
}

\author{
Ali Kılıç, Mehmet Erkan Kütük*, Sadettin Kapucu \\ Gaziantep Üniversitesi, Mühendislik Fakültesi, Makine Mühendisliği Bölümü 27310 Şehitkamil/Gaziantep, Türkiye \\ akilic@gantep.edu.tr@, *mekutuk@gantep.edu.tr $\mathbb{D}^{\mathbb{D}}$, kapucu@gantep.edu.tr $(\mathbb{D}$ \\ Makale gönderme tarihi:28.09.2020, Makale kabul tarihi: 21.05.2021
}

\begin{abstract}
$\ddot{O} \mathbf{z}$
Bir problemin yenilikçi/yaratıcı çözümlerinin bulunabilmesi için en önemli adım problem tanımının yeniden düzenlenmesidir. Problem tanımını verildiği gibi alıp kullanmak, problem çözücünün bakış açısını kısıtladığı gibi tamamen yanlış yola da yönlendirebilir. Bununla birlikte çelişki içeren yenilikçilik ve yaratıcılık gerektiren problemlerdeki çelişkileri belirlemek zor olabilmektedir. Bu çalışmada, problem tanımının düzenlenmesine ve çelişkilerin belirlenmesine yönelik geliştirilmiş olan 'problemi yeniden tanımlama' algoritmasının endüstride karşılaşılan 'taşıma sırasında ortaya çıkan palet devrilme' sorununa uygulanması sunulacaktır. Problemin yeniden nasıl ifade edileceğinden ve bunun için izlenen süreçten bahsedilecektir. Elde edilen yeniden tanımlamalar ile çözüme erişmek için kullanılabilecek TRIZ yöntemleri önerilecektir.
\end{abstract}

Anahtar Kelimeler: Çelişkiler, problem formülatörü, problemin yeniden tanımlanması, TRIZ

\section{Redefining the Problem in Problem Solving with TRIZ: Problem Formulation}

\begin{abstract}
The most important step to find the innovative / creative solutions of a problem is the reorganization of the problem definition. Using the problem definition as given not only can restrict the point of view of the problem solver but also can lead him/her to the wrong path. However, it can be difficult to identify contradictions in problems that require contradictory innovation and creativity. In this study, the 'redefine the problem' algorithm, which was developed for the regulation of the problem definition and the determination of the contradictions, will be applied to the 'pallet tipping that occurs during transportation' problem encountered in the industry. How to re-express the problem and the process followed for it will be discussed. TRIZ methods that can be used to reach the solution with the obtained redefinitions will be proposed.
\end{abstract}

Keywords: Contradictions, problem formulator, problem redefinition, TRIZ

\section{GİRIŞ}

Tasarım ve problem çözmenin ilk aşaması problemin tanımlanmasıdır. Birileri tarafindan tanımlanan ya da çerçevesi çizilen problemin ilk önce problem çözücü/ler tarafindan yeniden ifade edilmesi gerekir. Problemin/sorunun bütün yönleriyle anlaşılması ve geniş bir açıdan bakılabilmesine olanak sağlayacak şekilde yeniden düzenlenmesi oldukça önemlidir. Böylelikle gerçekte çözülmesi gereken problemin ele alınması sağlanabilir. Problemi yeniden tanımlama adımı, tasarım ve problem çözmenin ilk adımı olarak bilinmesine karşın hem ihmal edilir hem de zor bir iştir, çünkü gerçek problemler sıklıkla çeşitli şekillerde gizlenir. Bilgi okyanusunun içerisinden gerçek problemi soyutlayıp çıkarmak yetenekli bir kişinin bile çok zamanını alabilir. Kötü ifade edilen veya eksik bir biçimde ortaya konulan bir problem, problem çözücüyü imkânsız veya kabul edilemez/yanlış çözümlere yönlendirebilir. İkincil ya da üçüncül problemlere odaklanarak geçici çözüm bulunmasını sağlanabilir, ancak harcanan zamanı, parayı ve emeği en aza indirebilmek için gerçek problemi bulmak ve çözmek gereklidir. Problemi yeniden tanımlama ve birincil problemi belirleme yöntemleri arasında nedensel haritalama yöntemleri çoğu zaman merkezi bir rol oynamaktadır. Çünkü doğru kök nedenlerini bulmak, iyileştirme için fikir bulmakta kritik öneme sahip olabilmektedir. 
Çözümü zor olan problemler genellikle çelișki içerirler ve bu çelişkileri problem tanımından ortaya çıkarmak genellikle zor olabilmektedir. Ayrıca, problem çözümüne farklı yollardan yaklaşmak için tetikleyici yeniden tanımlanmış problem cümlelerine ihtiyaç vardır. İşte problem formülatorü, hem problemdeki çelişkileri açıkça ortaya koyduğu gibi, hem de yararlı fonksiyonlar ve zararlı fonksiyonlar ile ilgili problem çözme için birçok yönlendirici problem tanımları vermektedir. $\mathrm{Bu}$ çalışmada, problem formülatörünün endüstriyel bir probleme uygulanmasından bahsedilecektir. Palet üzerine robotlar vasıtasıyla dizilen torba paketlerin taşıma sırasında devrilme problemini önlemeye yönelik bir çalışmadır. Firma yetkilileri tarafından yapılan problem tanımına, problem formülasyonun uygulanması sonucundaki grafiksel gösterim ve yönlendirici problem cümlelerinin oluşturulması verilecektir. $\mathrm{Bu}$ cümlelerin yönlendirilmesi sonucunda problemlerin nasıl çözüleceği konusu ise uygun TRIZ yöntemlerinin seçilerek kullanılmasına kalacaktır. Dolayısıyla, bu çalışma sonucunda endüstriyel problemin çözümüne yönelik öneriler getirmekten ziyade, hangi yöntemlerin kullanılabileceğine dair önerilerde bulunulacaktır.

\section{LITERATÜR ARASTTIRMASI}

Bir sorunun nedenlerini analiz etmek için Zihin Haritalama, Balık Kılçıı̆ 1 , FMEA (Hata Türleri ve Etki Analizi), Sebep-Sonuç Analizi, Problem Formülatorü gibi pek çok yöntem vardır (Lee ve ark., 2018). Ancak, bunların içerisindeki özellikle üretim alanındaki yenilik projelerinde daha sı kullanılan kök nedensel ilişki haritalama yöntemlerinden birisi olan Problem Formülatorü dikkat çekmektedir. "İnovasyon nasıl yapılır?" sorusuna son zamanlarda "Yenilikçi/Yaratıcı Problem Çözme Teorisi, TRIZ" yöntemi önerilmektedir. TRIZ kolayca öğrenilebilip, öğretilebilen, kişiye/kişilere bağlı olmayan, sistematik bir biçimde uygulanabilen, dünya patentlerindeki teknolojilerinin kullanılmasina olanak veren popüler bir yöntemdir (Zusman ve Zlotin, 1999; Orloff, 2003; Şener, 2006; Durgun ve Doruk, 2015; Kaya, 2016; Ekmekçi ve Nebati, 2019).

Bir sistemin yararlı ve zararl fonksiyonları arasındaki bağlantıyı göstermek için basit bir sebepsonuç grafiğinin oluşturulması, problem formülasyon süreci olarak adlandırılır. Problem Formülatorü TRIZ yöntemlerinde kullanılabilecek problem tanımlarını doğrudan verebilmesi nedeniyle tercih edilmektedir
(Çeliktürk ve ark., 2005). Problem formülatörü, kök neden analizini yapmak, yenilikçi yaratıcı problem çözümünü gerektiren çelişkileri ve çözme yönleri oluşturmak için geliştirilen bir yazılım bir modülüdür (Zlotin ve ark., 1994). "5 Neden Sorusu” basit ağaç yapısı yerine zincir yapı kullanır. Dolayısıyla, yararlı fonksiyonlar, zararlı fonksiyonlar ve çelişkiler arasındaki ilişkiler görsel olarak gösterilebilmektedir. $\mathrm{Bu}$ gösterimlerden birçok problem çözme tanımları oluşturulabilmektedir (Terninko ve ark., 1996).

\section{SEPERATÖR PROBLEMI}

Çocuk bezi makinelerinde üretilen bezler ürün ölçülerine göre paketlenmektedir ve bu paketlerde daha sonra Pazar tarafından belirlenmiş adetlerde torbalara doldurulmaktadır. Paketleme makinelerinden çıkan torbalar konveyör aracılığıyla depoya sevk edilerek, robotlar yardımı ile paletler üzerine belirlenen şekilde dizilmektedir. $\mathrm{Bu}$ dizim sırasında torba katmanları arasında kaymalar yaşanmaktadır (Kapucu ve ark., 2019 ${ }^{\mathrm{a}}{ }^{\mathrm{b}}$ ). Katmanlara seperatör konulmaksızın, paketler paletlere dizilirken/dizildiğinde veya konveyörler üzerinde harekete başlandığında Şekil 1 ve 2'de görüldügü gibi devrilmeler/ayrılmalar olmaktadır.

$\mathrm{Bu}$ kaymaları önlemek ve düz bir zemin oluşturmak adına robot sisteminde katlar arasına seperatörler yerleştirilmektedir. $\mathrm{Bu}$ seperatörler yurtdışı menşeli olan 2 yüzü kaydırmaz materyalle kaplanmış bir yüzeye sahiptirler. Tedariki yurt dışından olduğu için hem maliyet hem de temrin konusunda sıkıntılar yaşanmaktadır. Genellikle de birkaç kullanımdan sonra deformasyona uğradıkları için kullanılamaz duruma gelmektedirler. Yerli seperatörler piyasada mevcuttur ancak, ithal muadilleri ile kıyaslandığında devrilmeleri engellemede yetersiz kalmaktadır.

Paletleme işlemi tamamlandığında paletler, paketleme hattından alınıp stok alanına taşınıncaya kadar konveyörler üzerinde birkaç defa dur kalk yapmaktadır. $\mathrm{Bu}$ hareketler yatay düzlemde olmaktadır. Ayrıca bir defa da dikey yönde dur kalk yapmaktadır. Bu hareketlerin haricinde ana depoya taşınırken de çatallı taşıyıcı ile taşınmaktadır. Uygun seperatör olmadığında paketler dur-kalk sırasında ve çatallı taşıyıcıda oluşan ivmelenmeler nedeniyle birbirleri üzerinde kolayca hareket ederek devrilmektedir.

Ayrıca, seperatör olmasına rağmen depolama alanında bekleyen bu ürünler bir süre sonra kaymaya 
başlamaktadır. $\mathrm{Bu}$ nedenle depolama alanında hem yetersiz alan hem de görüntü kirliliği oluşmaktadır. Dağılan paletlerin yeniden düzenlenmesi, sayımı ve kontrolü ekstra bir iş yükü oluşturmaktadır. Firma seperatör problemine çözüm aramaktadır.
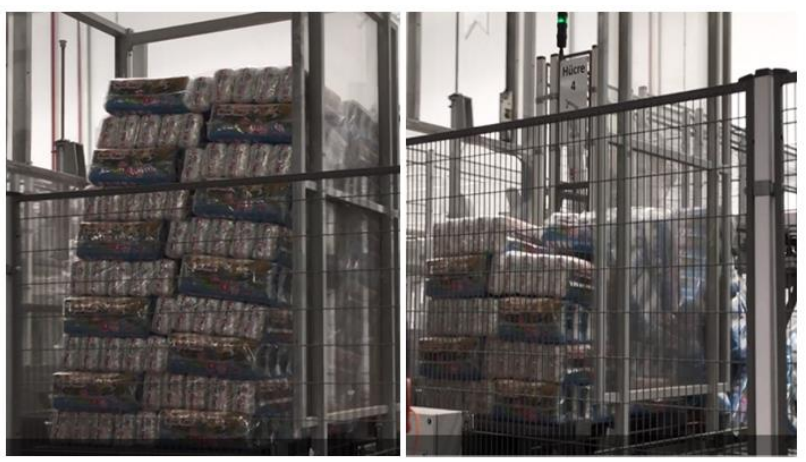

Şekil 1. Taşıma arabasının ivmelenmesine bağlı olarak devrilmeler (Kapucu ve ark., 2019a)
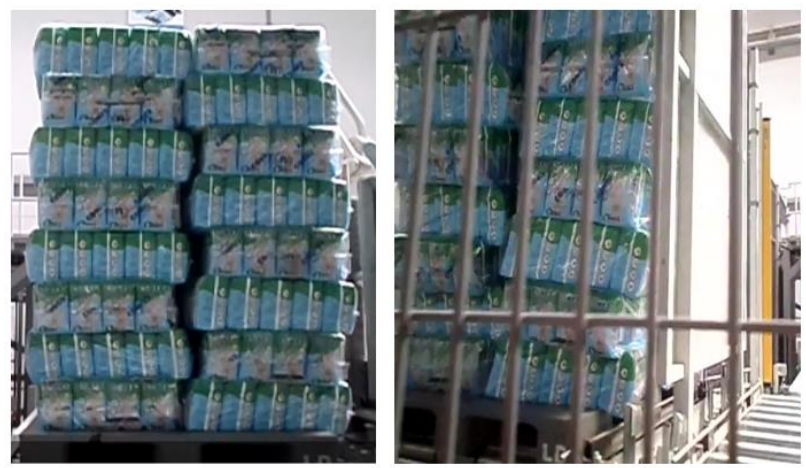

Şekil 2. Palet üzerinde dizim sırasında torbaların birbirinden ayrılması (Kapucu ve ark., 2019ª)

\section{PROBLEM FORMÜLASYONU}

Problem formülasyon grafiğinin oluşturulması sırasında Zararlı (ZF) ve Yararlı Fonksiyonlar (YF) arasında genellikle üç tür bağlantı vardır. Bu bağlantılar Şekil 3'te verilmiştir. $\mathrm{Bu}$ şekilde problemde tanımlanan olumlu ya da olması gereken nitelikler (YF) daire içerisinde, sistemin çalışmasını olumsuz yönde etkileyen nitelikler (ZF) ise dikdörtgenler ile gösterilmiştir. Yakın ilişkide olan ZF ya da YF arasındaki bağlantı da yine değişik oklarla gösterilmiştir.

$\mathrm{Bu}$ ilişkiler aynı zamanda sebep sonuç cümlelerini vermektedir. Yukarıdaki tanımlanan problem incelendiğinde yararlı fonksiyonlar/işlevler ile zararlı fonksiyonlar/işlevler arasındaki bağlantıları şu şekilde ifade etmek mümkündür.

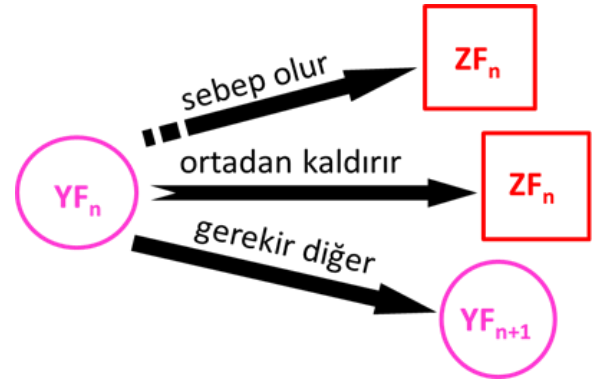

Şekil 3. Zararlı (ZF) ve Yararlı Fonksiyonları (YF) arasındaki üç tür bağlantı

(Seperatör) gerekir (palet devrilmesini önlemek) için, (Seperatör) sebep olur [zaman kaybına],

(Seperatör) sebep olur [maliyet artışına],

(Seperatör) sebep olur [işlem karmaşıklığına],

(Seperatör) gerekir diğer (bağ oluşturmak) için,

(Seperatör) gerekir diğer (sürtünmeyi artırmak) için,

(Seperatör) gerekir (üst üste dizilen paketlerin ezilmesini önlemek) için,

(Forklift) gerekir (paletleri taşımak) için,

(Forklift) sebep olur [palet devrilmesine],

(Dur-kalk) gerekir (paleti konveyörde taşımak) için,

(Dur-kalk) sebep olur [palet devrilmesine],

(Paletlere paketleri dizmek) gerekir (depolamak) için,

(Paletleri taşımak) gerekir (depolamak) için.

Burada bahsedilen ZF ve/veya YF arasındaki bağlantıları (sebep sonuç ilişkilerini) grafik olarak bir bütün halinde Şekil 4'teki gibi göstermek mümkündür. $\mathrm{Bu}$ şekildeki numaralar dügüm noktalarını göstermektedir. Dügüm noktaları için; kötüleşen nitelikler için önleyici, olumlu nitelikler için alternatif ve hem sebebiyet veren hem de gerektiren çıkışları olan için de çelişki ifadeleri yazılabilir. Bu şekilde problem ile ilgili aşağıda da verildiği gibi, birçok alt problem ifadeleri oluşturulabilir. 
Research article/Araștırma makalesi DOI: 10.29132/ijpas.801326

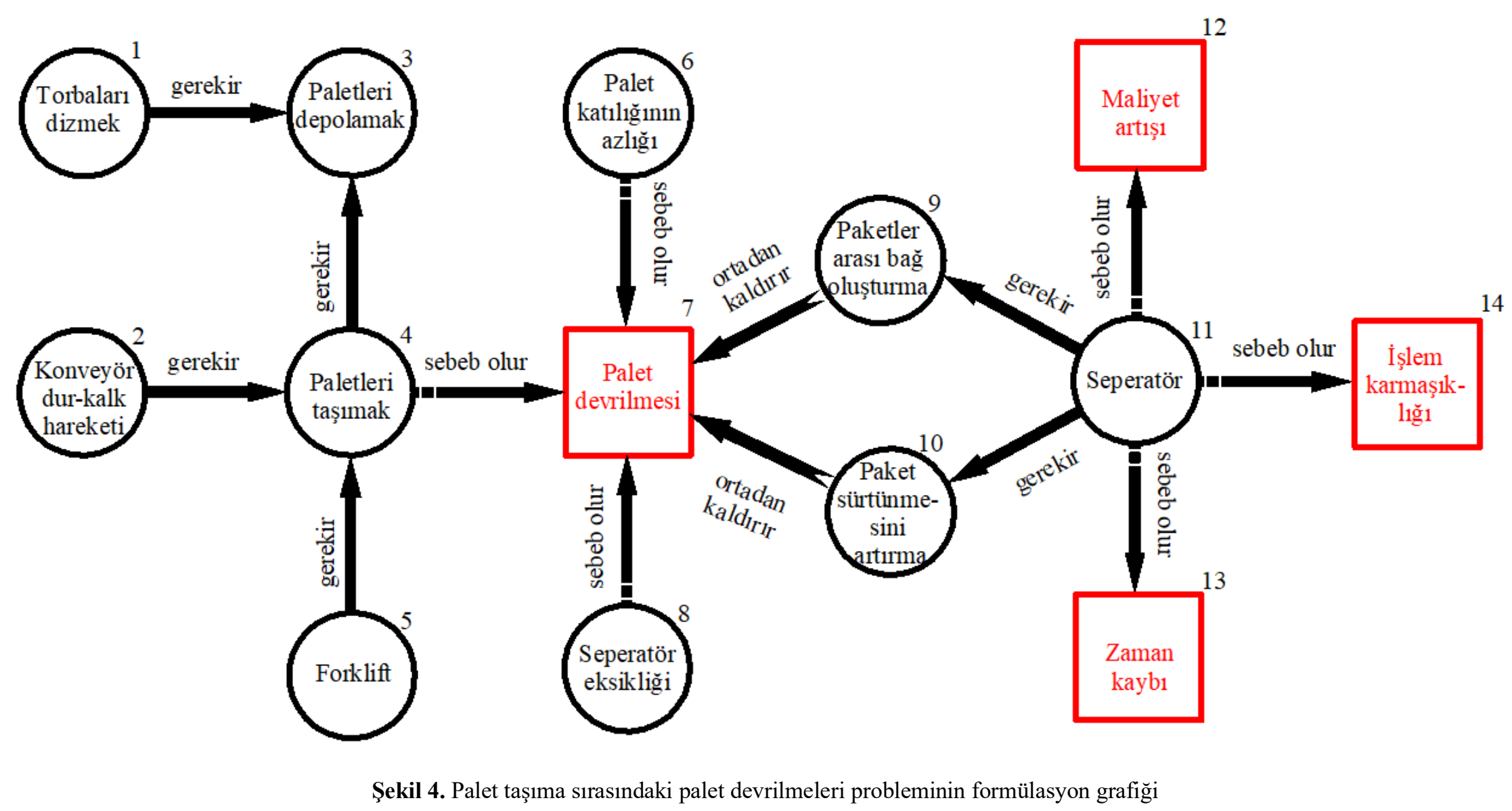


1a. (Paletleri depolamak) için (Torbaları dizme) gerektirmeyen alternatif bir yol bul.

1b. (Torbaları dizme)'nin geliştirilmiş bir yolunu bul.

2a. (Paletleri taşımak) için (Konveyör dur-kalk hareketi) gerektirmeyen alternatif bir yol bul.

2b. (Konveyör dur-kalk hareketi)'nin geliştirilmiş bir yolunu bul.

3a. (Paletleri depolamak) için, (Torbaları dizme)'yi sağlayan ve (Paletleri taşıma)'yı gerektirmeyen alternatif bir yol bul.

3b. (Paletleri depolama)'nın geliştirilmiş bir yolunu bul.

4a. (Paletleri taşıma) için, (Paletlerin depolanması)'nı sağlayan ve aynı zamanda [Palet devrilmesi]'ne sebep olmayan alternatif bir yol bul.

4b. (Palet taşıma)'yı geliştirmenin bir yolunu bul.

4c. ÇELISŞKIYİ çözmenin bir yolunu bul: (Palet taşıma), (Palet depolama)'yı sağlasın fakat [Palet devrilmesi]'ne sebep olmasin.

4d. (Palet taşıma) için, (Konveyör dur-kalk hareketi)'ni sağlayan ve aynı zamanda [Palet devrilmesini] engelleyen alternatif bir yol bul.

4e. (Palet taşıma) için, (Paletleri depolama)'yı sağlayan ve aynı zamanda (Forklift) gerektirmeyen alternatif bir yol bul.

5a. (Paletleri taşımak) için (Forklift) gerektirmeyen alternatif bir yol bul.

5b. (Forklift)'in geliştirilmiş bir yolunu bul.

6a. (Palet katılığının azlığı) durumunda [Palet devrilmesi]'ne sebep olmayan alternatif bir yol bul.

6b. (Palet katılığının azlığı)'nı geliştirmenin bir yolunu bul.

7a. (Palet taşıma) altındaki durumda (Paketler arası bağ oluşumu)'na gerek kalmaksızın [Palet devrilmesi]'ni ortadan kaldırmak, azaltmak veya önlemek için bir yol bul.

7b. (Palet katılığının azlığı) altındaki durumda (Paketler arası bağ oluşumu)'na gerek kalmaksızın [Palet devrilmesi]'ni ortadan kaldırmak, azaltmak veya önlemek için bir yol bul.

7c. (Seperatör eksikliği) altındaki durumda (Paketler arası bağ oluşumu)'na gerek kalmaksızın [Palet devrilmesi]'ni ortadan kaldırmak, azaltmak veya önlemek için bir yol bul. 7d. (Palet taşıma) altındaki durumda (Paketler arası sürtünmeyi artırma)'ya gerek kalmaksızın [Palet devrilmesi]'ni ortadan kaldırmak, azaltmak veya önlemek için bir yol bul.

7e. (Palet katılığının azlığı) altındaki durumda (Paketler aras1 sürtünmeyi artırma)'ya gerek kalmaksızın [Palet devrilmesi]'ni ortadan kaldırmak, azaltmak veya önlemek için bir yol bul.

7f. (Seperatör eksikliği) altındaki durumda (Paketler arası sürtünmeyi artırma)'ya gerek kalmaksızın [Palet devrilmesi]'ni ortadan kaldırmak, azaltmak veya önlemek için bir yol bul.

7g. [Palet devrilmesi]'nden yararlanmanın bir yolunu bulun.

8a. (Seperatör eksikliği) durumunda [Palet devrilmesi]'ne sebep olmayan alternatif bir yol bul.

8b. (Seperatör eksikliği)'ni geliştirmenin bir yolunu bul.

9a. (Paketler arası bağ oluşturmak) için (Seperatör)'e gereksinim duymayan [Palet devrilmesi]'ni engelleyen alternatif bir yol bul.

9b. (Paletler arası bağ oluşturma)'nın geliştirilmiş bir yolunu bul.

10a. (Paketler aras1 sürtünmeyi artırmak) için (Seperatör)'e gereksinim duymayan [Palet devrilmesi]'ni engelleyen alternatif bir yol bul.

10b. (Paketler aras1 sürtünmeyi artırma)'nın geliştirilmiş bir yolunu bul.

11a. (Paketler arası bağ oluşturması) için (Seperatör) sağlayan ve aynı zamanda [Maliyet artışına]'na sebep olmayan alternatif bir yol bul.

11b. (Paketler arası bağ oluşturması) için (Seperatör) sağlayan ve aynı zamanda [İşlem karmaşıklığı]'na sebep olmayan alternatif bir yol bul.

11c. (Paketler arası bağ oluşturması) için (Seperatör) sağlayan ve aynı zamanda [Zaman kaybı]'na sebep olmayan alternatif bir yol bul.

11d. (Paketler aras1 sürtünmeyi artırmak) için (Seperatör) sağlayan ve aynı zamanda [Maliyet artışına]'na sebep olmayan alternatif bir yol bul.

11e. (Paketler arası sürtünmeyi artırmak) için (Seperatör) sağlayan ve aynı zamanda [İşlem karmaşıklığ1]'na sebep olmayan alternatif bir yol bul. 11f. (Paketler arası sürtünmeyi artırmak) için (Seperatör) sağlayan ve aynı zamanda [Zaman kayb1]'na sebep olmayan alternatif bir yol bul.

$11 \mathrm{~g}$. (Seperatör) geliştirmenin bir yolunu bul. 
11h. ÇELİŞKIYYI çözmenin bir yolunu bul: (Seperatör), (Paketler arası bağ oluşumu)'nu sağlasın fakat [Zaman kaybi]'na sebep olmasin.

11i. ÇELISSKIYII çözmenin bir yolunu bul: (Seperatör), (Paketler arası bağ oluşumu)'nu sağlasın fakat [İşlem karmaşıklığı]'na sebep olmasın.

11j. ÇELIŞSKIYİ çözmenin bir yolunu bul: (Seperatör), (Paketler arası bağ oluşumu)'nu sağlasın fakat [Maliyet artış1]'na sebep olmasın.

11k. ÇELIŞKIYİ çözmenin bir yolunu bul: (Seperatör), (Paketler arası sürtünmeyi artırma)'y1 sağlasın fakat [Zaman kaybi]'na sebep olmasın.

111. ÇELIŞKIYII çözmenin bir yolunu bul: (Seperatör), (Paketler arası sürtünmeyi artırımı)'nı sağlasın fakat [İșlem karmașıklığı]'na sebep olmasın. $11 \mathrm{~m}$. ÇELIŞKIYİ çözmenin bir yolunu bul: (Seperatör), (Paketler arası sürtünme artırma)'y1 sağlasın fakat [Maliyet artış1]'na sebep olmasın.

12a. [Maliyet artış1]'nı ortadan kaldırmak, azaltmak veya önlemek için bir yol bul.

12b. [Maliyet artış1]'ndan yararlanmanın bir yolunu bulun.

13a. [Zaman kaybi]'nı ortadan kaldırmak, azaltmak veya önlemek için bir yol bul.

13b. [Zaman kaybi]'ndan yararlanmanın bir yolunu bulun.

14a. [İşlem karmaşıklığı]'nı ortadan kaldırmak, azaltmak veya önlemek için bir yol bul.

14b. [İşlem karmaşıklığı]'ndan yararlanmanın bir yolunu bulun.

Yukarıda verilmiş problemin yeniden tanımlama cümleleri ile TRİ yöntemleri kullanılmak istenilebilir. $\mathrm{Bu}$ durumda, probleme özgü tanımlamalar yerine yine TRIZ'de bahsedilen teknik parametreler/özellikler'in belirtilmesi gerekecektir. İlk on yedi problem tanım cümlesine bakıldığında, bunların teknik sistemin üst bileşenleri ile ilgi oldukları görülmektedir. Özellikle, fonksiyon iyileştirme veya alternatif yol bulma ile ilgili olanlar için teknik istemlerin ideale/mükemmelliliğe giden aşamadaki aralığı kapatmak için etkiler veri tabanı kullanımı önerilebilir. 7c, 9a cümlesi TRIZ'deki Fiziksel çelişkiler yöntemine gönderme yapmaktadır. Seperatör olmasin ama palet devrilmesi de olmasın, diğer bir deyişle sistem (seperatör) olmasın fakat fonksiyon (palet devrilmesinin önlenmesi) sanki seperatör varmış gibi yerine getirilsin olarak ifade edilebilir. Fiziksel çelişkilerin çözümü için ayrıştırma prensipleri kullanılmaktadır (Kapucu ve ark., 2019b). "Paketler arası bağ oluşturulması" ve "paketler arası sürtünmeyi artırmak için" ile başlayan cümleler ise teknik sistemdeki "sürtünme" parametresinin "iyileştirilmesi"/“artırılması"nı içermektedir. Bunun için ise yine TRIZ'in çözüm bulma yöntemlerinden olan ideal nihai sonuca erişmek için kullanılan TRIZ etkiler veri tabanından çözüm önerilerine erişilebilir (Kapucu ve ark., 2019a). Çelişkiler içeren cümlelere bakıldığında bazılarının doğrudan TRIZ'de problemleri ifade etmek için kullanılan 39 teknik parametre ile ifade edildikleri görülmektedir; "Zaman kaybı", "İşlem karmaşıklığı" gibi. Teknik parametrelerden bazıları ise üstü kapalı bir biçimde tanımlı olup bunların da problem cümlelerinden kolayca çıkarılabilmesi mümkündür. Örneğin, "Güvenilir olması", "Şekil" (palet bütünlüğünün korunmas1), Nesnenin etkilendiği zararlı faktörler, "Verimlilik" ve benzerleri gibi. O halde, oluşan problem tanımlarından iyileştirilmek istenilen ya da kötüleşen teknik parametreler kolayca belirlenebilir. Dolayısıyla, teknik çelișkilerin çözümü için çelișkiler matrisi kullanılarak çözüm bulmak olasıdır (Çeliktürk ve ark., 2005). Tüm bunların haricinde, palet devrilmesi probleminin "Operasyon Alanı"nın katmanları arası olduğu problem tanımlarından anlaşılmaktadır. Buranın "Madde-Alan Modeli" yapılıp, 76 standart çözümden uygun olanları ile farklı çözüm önerileri sunulabilir. Tüm bu anlatılanlar dikkate alındığında, problem formülasyonunun problemin detaylı anlaşılması ve kullanılabilecek TRIZ yöntemlerinden hangilerinin seçilebileceği konusunda oldukça etkili bir yöntem olduğu görülmektedir.

\section{SONUÇLAR}

Özellikle, yenilikçilik/yaratıcılık gerektiren zor problemler olarak nitelenen ve çelişki barındıran problemlerde çelişkilerin elde edilmesi tanımlanan problemden zaman zaman daha zor olmaktadir. Yenilikçi/yaratıcı problem çözme teorisine eklenen bu problem formülasyonu ile problemi çözmek için birçok yönlendirici cümleler oluşturulabilmekte, kök nedeni belirlenebilmekte ve çelişkiler kolayca elde edilebilmektedir. Bir yazılım programının bir parçası olarak geliştirilen ve patent ile koruma altına alınan bu yöntemin patent süresinin dolması göz önüne alındığında herkes tarafından kullanılmasında bir sakınca yoktur. Bu çalışmadan da anlaşıldığı üzere, tanımlı adımlar izlenildiğinde problem çözücülere 
problemin yeniden tanımlamasına yönelik büyük kolaylıklar sağlanmaktadır. Çözüm için alternatif yönlere bakma konusunda, yöntemleri belirlemede ve hatta çözüm üretmede oldukça yardımcı olduğu görülmektedir.

\section{ÇIKAR ÇATIŞMASI BEYANI}

Yazarlar bu makale ile ilgili herhangi bir çıkar çatışması bildirmemektedir.

\section{ARAŞTIRMA VE YAYIN ETİĞİ BEYANI}

Yazarlar bu çalışmanın araştırma ve yayın etiğine uygun olduğunu beyan eder.

\section{KAYNAKLAR}

Çeliktürk, E. E., Kapucu, S. ve Yıldırım, N. (2005). Kavramsal tasarımda bir problemin tanımlanması ve yenilikçi- yaratıcı problem çözme metodolojisi ile çözüm önerileri. Makina Tek, Aylık İmalat ve Teknoloji Kültürü Dergisi, 92, 116-123.

Durgun, İ. ve Doruk, E. (2015). TRIZ yaklaşımını kullanarak önden çarpmalı trafik kazalarında yayaların güvenlik koşullarının iyileştirilmesi. AKÜ FEMÜBİ, 15, 1-6.

Ekmekçi, İ. ve Nebati, E.E. (2019). TRIZ methodolody and applications. Procedia Computer Science, 158, 303-315.

Kapucu S., Deniz M., Culfa G., Doğan B., Turan B., Yüksel M. V. ve Akdemir A. (2019a). İdeal sonuç yöntemini kullanarak taşıma sırasında palet stabilizesine ilişkin kavramsal tasarım. 4. Uluslararası Mühendislik, Mimarlık ve Tasarım Kongresi, İstanbul, Türkiye, 23-24 Nisan.

Kapucu S., Deniz M., Culfa G., Doğan B., Turan B., Yüksel M. V. ve Akdemir A. $\left(2019^{b}\right)$. TRIZ fiziksel çelişkiler yöntemi ile taşıma sırasında palet stabilitesine ilișkin kavramsal tasarım. 4. Uluslararası Mühendislik, Mimarlık ve Tasarım Kongresi, İstanbul, Türkiye, 23-24 Nisan.

Kaya, M. O. (2016). Dünya'da ve Türkiye'de TRIZ kullanan şirketler. https://medium.com/@metinokaya/dünyada-vetürkiye-de-triz-kullanan-șirketler-52fb26beea8c, 23/09/2020.

Lee, M.G., Chechurin, L. ve Lenyashin, V. (2018). Introduction to cause-effect chain analysis plus with an application in solving manufacturing problems. International Journal of Advanced Manufacturing Technology, 99, 2159-2169.

Orloff, M. A. (2003). Inventive thinking through TRIZ, a practical guide. Springer-Verlag.

Şener, S.D. (2006). TRIZ: yaratıcı problem çözme teorisi ve diğer problem çözme yöntemleriyle karşılaştırma.
Yüksek Lisans Tezi, İstanbul Teknik Üniversitesi Fen Bilimleri Enstitüsü.

Terninko, J., Zusman, A. ve Zlotin, B. (1996). Step-by-step TRIZ: creating innovative solution concepts. Responsible Manegement Inc.

Zlotin, B., Bushuev, D., Haimov, E., Malkin, S., Zusman, A., Tikhonov, A. ve Pevnev, V. (1994). Automated problem formulator and solver, Patent no: US $5,581,663$.

Zusman, A. ve Zlotin B. (1999). Overview of creative methods. https://www.metodolog.ru/trizjournal/archives/1999/07/e/index.htm, 23/09/2020. 